\title{
A drospirenone-containing oral contraceptive improved bleeding pattern and personal satisfaction in 914 women from Jordan, Lebanon and Syria
}

\author{
Ramzi Finan $^{1}$, Abeer Wasfi Annab ${ }^{2}$, Salwa Abdalla ${ }^{3}$, Farid Bedran ${ }^{4}$, Mazen El-Zibdeh ${ }^{5}$, \\ Lina Shahen ${ }^{6}$, Christoph Gerlinger ${ }^{7}$, Erich Solomayer ${ }^{8}$, Kubilay Ertan $^{9}$, Jan Endrikat ${ }^{7,8^{*}}$ \\ ${ }^{1}$ Universite St. Joseph, Hotel Dieu de France, Beirut, Lebanon \\ ${ }^{2} \mathrm{Al}$ Amal Maternity Hospital, Amman, Jordan \\ ${ }^{3}$ Private Clinic-Al-ShahBandar Square, Damascus, Syria \\ ${ }^{4}$ Serhal Hospital-Rabieh, Beirut, Lebanon \\ ${ }^{5}$ Islamic Hospital, Amman, Jordan \\ ${ }^{6}$ Private Clinic-Al-Enshaat-Ragheb Al-Jamali Street, Homs, Syria \\ ${ }^{7}$ Bayer Healtcare, Bayer AG, Berlin, Germany; ${ }^{*}$ Corresponding Author: jan.endrikat@bayer.com \\ ${ }^{8}$ Department of OB/GYN, Universitätskliniken des Saarlandes, Homburg/Saar, Germany \\ ${ }^{9}$ Department of OB/GYN, Leverkusen Municipal Hospital, Leverkusen, Germany
}

Received 8 April 2013; revised 9 May 2013; accepted 1 June 2013

Copyright (C) 2013 Ramzi Finan et al. This is an open access article distributed under the Creative Commons Attribution License, which permits unrestricted use, distribution, and reproduction in any medium, provided the original work is properly cited.

\section{ABSTRACT}

Aim: We assessed bleeding pattern, tolerance and patient satisfaction of an oral contraceptive containing $3 \mathrm{mg}$ drospirenone and $30 \mathrm{mcg}$ ethinyl estradiol (DRSP/EE) under real-life conditions. Study Design: We performed a multicenter, prospective, 6-cycle, observational study in Canada, Europe and the Middle East. Detailed analyses of the three Middle East countries, Jordan, Lebanon and Syria were presented here. The efficacy variables included an assessment of bleeding patterns, premenstrual symptoms of water retention and patient satisfaction, as determined by a visual analogue scale. Results: A total of 914 women were enrolled. The percentage of women with intermenstrual bleeding decreased from $37.4 \%, 48.7 \%$ and $32.2 \%$ at baseline to $9.7 \%$, $6.1 \%$ and $10.9 \%$ at the end of cycle 6 in Jordan, Lebanon and Syria, respectively $(<0.0001)$. Also, the percentage of women with dysmenorrea decreased sharply in all three countries $(p<0.0001)$. Amenorrhea decreased significantly in Lebanon and Syria $(p<0.005)$. In addition, signs of water retention like abdominal bloating, breast tenderness and swelling of extremities decreased significantly over the course of 6 treatment cycles $(p<0.001)$. Patient satisfaction increased for all investigated items. Upon completion of the study, $82.7 \%$ of women answered "Yes" to continue treatment with this oral contraceptive. Conclusion: The oral contraceptive containing 3 $\mathrm{mg}$ drospirenone and $\mathbf{3 0} \mathrm{mcg}$ ethinyl estradiol has beneficial effects on bleeding pattern, symptoms of water retention and patient satisfaction.

Keywords: Bleeding Pattern; Tolerance; Drospirenone; Oral Contraception

\section{INTRODUCTION}

The combined oral contraceptive (COC) containing 3 $\mathrm{mg}$ drospirenone (DRSP) and $30 \mathrm{mcg}$ ethinyl estradiol (EE) $\left(\mathrm{DRSP} / \mathrm{EE}, \mathrm{Yasmin}^{\circledR}\right)$ shows unique features that have not been seen in other COCs. While it is characterized by a high contraceptive efficacy, excellent cycle control and a low incidence of adverse events [1-3], the progestogen DRSP used in this COC, a $17 \alpha$-spirolactone derivative, is of particular interest because of its distinct pharmacological profile. In addition to a potent progestogenic activity, it provides anti-androgenic and anti-mineralocorticoid activity [4-8]. The anti-mineralocorticoid activity is detectable at therapeutic doses, a feature that is not possessed by any other synthetic progestogen, and it reduces estrogen-related water retention [1].

In the current study, we assessed bleeding pattern, tolerance and patient satisfaction during intake of DRSP/EE. The purpose of this study was to yield clinical data during day-to-day use of DRSP/EE under real-life conditions. 
Here we present data of an analysis for three Middle East countries, i.e., Jordan, Lebanon and Syria. The whole data set comprising 3488 women in Europe, the Middle East and Canada was published in 2009 [9].

\section{MATERIALS AND METHODS}

\subsection{Study Design}

We performed this prospective, open-label, multicenter, observational, one-arm cohort study at 17 centers in the Middle East (Jordan: 2 sites; Lebanon: 7 sites; Syria: 8 sites). This is a planned sub-analysis, the overall data were reported earlier [9].

The study was conducted in accordance with the ethical principles of the Declaration of Helsinki. Ethics Committees reviewed and gave their consent to the study material before the study started. The study duration was 6 treatment cycles.

\subsection{Study Population}

Women starting hormonal contraception with DRSP/ EE (first-ever users or switching from another product) were eligible for this trial. We recruited in private and public centers. Except for the medication and the medical evaluations, no incentives were provided. The prescribing physician was obliged to exclude women with contraindications as stated in the Product Monograph, which were not different from other combined oral contraceptives in the respective country. All women gave their informed consent before participating in the study.

\subsection{Study Preparation and Intake Schedule}

All eligible women received the study drug for six cycles. The study medication (produced by Bayer Pharma AG, Berlin, Germany) was supplied in calendar packs containing 21 active pills with $3 \mathrm{mg}$ DRSP and $30 \mathrm{mcg}$ EE. Each cycle consisted of a 21 day period during which the patient took one tablet daily, followed by a seven-day pill-free interval. When the seven-day pill-free period was finished, the women started taking the active pill from a new blisterpack.

\subsection{Study Assessments}

Bleeding pattern: We collected data on bleeding pattern at baseline and after 3 and 6 cycles. Intermenstrual bleeding (bleeding during pill-intake), dysmenorrhea, amenorrhea and intensity (weak, normal, heavy) and duration of monthly withdrawal bleeding (days) were recorded in the case report form during the visit with the investigator.

Tolerance: We recorded physical signs of water retention (abdominal bloating, breast tenderness, swelling of extremities) at the same time points using a questionnaire that was filled out by the women. Body weight was determined during the visit always using the same scales. Adverse events were not solicited but documented when mentioned by the patient.

Patient satisfaction: At baseline and after 6 cycles of treatment, a visual analog scale (VAS) diary was completed by the women to document satisfaction with certain parameters. In the diary, women made a mark on a $10-\mathrm{cm}$ scale with $0=$ lowest level and $10=$ maximum level of imaginable satisfaction.

\subsection{Statistical Methods}

The primary target variables of the study were the bleeding characteristics, intracyclic bleeding, dysmenorrhea, and amenorrhea. The population of interest was the intent-to-treat population, which consisted of all patients that entered the study. Continuous variables were analyzed by descriptive statistics including the number of observations, arithmetic mean, and standard deviation. Categorical variables were analyzed by absolute and relative frequency counts. Missing values were not replaced during the statistical analysis.

Changes from baseline were tested for selected target variables. For continuous variables, the null hypothesis of no treatment effect was tested using the one-sample ttest. For categorical variables, the null hypothesis of no treatment effect was tested using Bowker's test for paired data using the all categories of symptoms severity, e.g. "no", "light", "moderate", and "strong". For simplicity, the figures present the proportion of women with symptoms regardless of severity. The rate of nulliparae, smoking, and of OC use before study start was compared between the countries by a $\chi^{2}$-test. All tests were performed at a two-sided significance level $\alpha$ of $5 \%$. No correction for multiple testing was done, as appropriate for exploratory analyses.

\section{RESULTS}

\subsection{Study Population}

We enrolled 914 women, 227 in Jordan, 273 in Lebanon and 414 in Syria. Apart from the percentage of nulliparae (higher in Lebanon) and the percentage of women who used OCs before start of study (higher in Jordan), the study populations in the three countries were very similar. All demographic data is shown on Table 1.

\subsection{Efficacy}

Cycle control: The percentage of women with intermenstrual bleeding decreased from $37.4 \%, 48.7 \%$ and $32.2 \%$ at baseline to $9.7 \%, 6.1 \%$ and $10.9 \%$ at the end of cycle 6 in Jordan, Lebanon and Syria, respectively, $(<0.0001)$. Also, dysmenorrhea significantly decreased in all countries, most prominently in Lebanon, from $69.2 \%$ 
to $13.6 \%$. Amenorrhea was relatively stable in Jordan but decreased remarkably in Lebanon and Syria $(p<0.0046$ and $\mathrm{p}<0.0001$, respectively) (Figure 1).

Table 1. Demographic and baseline characteristics.

\begin{tabular}{cccc}
\hline & $\begin{array}{c}\text { Jordan } \\
(\mathrm{n}=227)\end{array}$ & $\begin{array}{c}\text { Lebanon } \\
(\mathrm{n}=273)\end{array}$ & $\begin{array}{c}\text { Syria } \\
(\mathrm{n}=414)\end{array}$ \\
\hline Age (years) & $29.6 \pm 6.1$ & $28.1 \pm 6.0$ & $28.6 \pm 6.2$ \\
Height (cm) & $163.8 \pm 5.6$ & $164.6 \pm 6.2$ & $162.9 \pm 7.4$ \\
Body weight $(\mathrm{kg})$ & $65.3 \pm 10.5$ & $62.4 \pm 9.2$ & $66.3 \pm 11.3$ \\
Body mass index (kg/m²) & $24.3 \pm 3.7$ & $23.1 \pm 3.2$ & $25.2 \pm 7.0$ \\
$\begin{array}{c}\text { Nulliparae (\%) } \\
\text { Prevalence of current } \\
\text { smoking (\%) }\end{array}$ & $41(18.1)$ & $73(26.7)^{*}$ & $68(16.4)$ \\
$\begin{array}{c}\text { OC use before study } \\
\text { start (\%) }\end{array}$ & $113(49.8)^{*}$ & $98(35.9)$ & $160(38.6)$ \\
\hline
\end{tabular}

${ }^{*} \mathrm{p}<0.01 \mathrm{OC}=$ oral contraceptive. Data are expressed as means $\pm \mathrm{SD}$ or $\mathrm{n}(\%)$ of women.

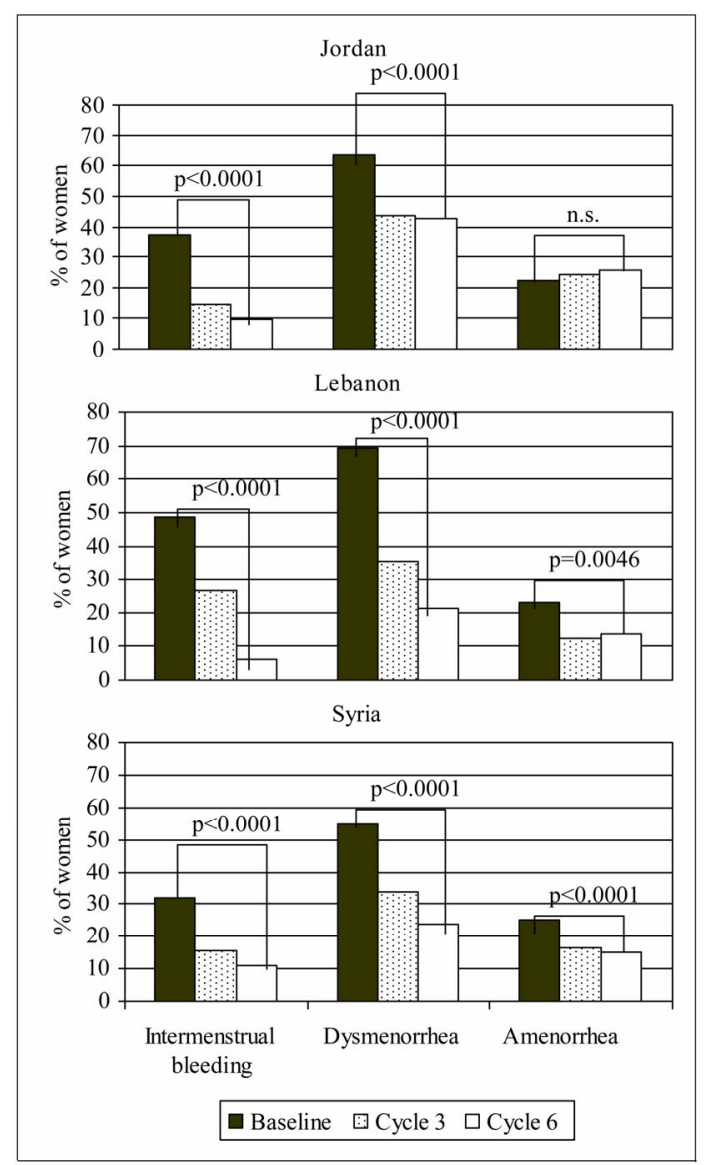

Figure 1. Cycle control at baseline and after 3 and 6 cycles. The statistical tests were performed on the intensity of the symptoms (see statistical methods section). There was a significant alleviation of symptoms from severe and moderate towards mild although the number of women with symptoms depicted in the graphs for simplicity remained constant in some instances.
The percentage of women experiencing weak withdrawal bleeding rose from $13.2 \%, 6.6 \%$ and $8.2 \%$ in Jordan, Lebanon and Syria, respectively, to $18.4 \%, 25.5 \%$ and $34.1 \%$ after cycle 6 while the frequency of heavy bleedings showed a marked decrease from $22.5 \%, 34.8 \%$ and $22.9 \%$ to $3.6 \%, 1.9 \%$ and $1.0 \%$, respectively. The number of women with normal bleedings showed a moderate increase (Figure 2).

The monthly withdrawal bleeding duration decreased during treatment by more than one day for all countries (data not shown).

Satisfaction: For all questions concerning patient satisfaction, a positive trend $(+)$ could be seen. Mean values of all items increased on the VAS indicating increasing personal satisfaction (Table 2).

Upon completion of the study, $82.7 \%$ of women answered "Yes" to continue treatment with this oral contraceptive.

\subsection{Tolerance}

Clinical signs of water retention decreased steadily from baseline to end of cycle 6 for all three parameters. These effects were most prominent in the study populations of Lebanon and Syria. All decreases in all three

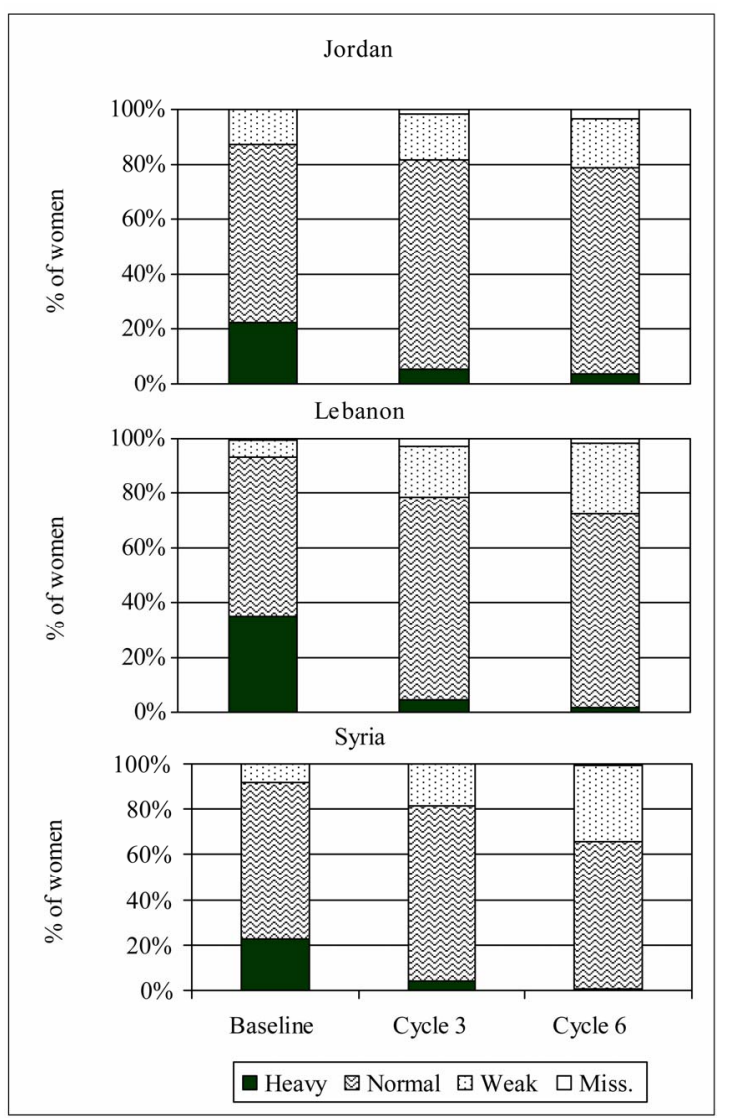

Figure 2. Bleeding intensity at baseline and after 3 and 6 cycles. 
Table 2. Perception of the current state of satisfaction ( $\mathrm{cm}$ on VAS $\pm \mathrm{SD}$ ).

\begin{tabular}{|c|c|c|c|c|c|c|c|c|c|c|}
\hline \multirow[b]{2}{*}{ Question } & \multirow[b]{2}{*}{ Points 0 and 10 on VAS } & \multicolumn{3}{|c|}{ Jordan } & \multicolumn{3}{|c|}{ Lebanon } & \multicolumn{3}{|c|}{ Syria } \\
\hline & & Baseline & Cycle 6 & Trend & Baseline & Cycle 6 & Trend & Baseline & Cycle 6 & Trend \\
\hline $\begin{array}{l}\text { Are you satisfied with } \\
\text { your body weight? }\end{array}$ & Not at all- totally satisfied & $5.0 \pm 3.0$ & $5.6 \pm 2.6$ & + & $5.3 \pm 2.8$ & $6.4 \pm 2.4$ & + & $4.9 \pm 3.2$ & $6.6 \pm 2.7$ & + \\
\hline $\begin{array}{l}\text { How do you feel } \\
\text { before menses? }\end{array}$ & Very bad-very well & $5.3 \pm 2.7$ & $6.7 \pm 2.2$ & + & $4.8 \pm 2.4$ & $6.5 \pm 2.1$ & + & $5.0 \pm 2.8$ & $7.0 \pm 2.3$ & + \\
\hline Your skin is $\cdots$ & Very impure_-clear & $6.3 \pm 2.7$ & $6.3 \pm 2.6$ & $+/-$ & $5.7 \pm 2.3$ & $7.1 \pm 2.0$ & + & $6.3 \pm 2.8$ & $7.9 \pm 1.9$ & + \\
\hline $\begin{array}{l}\text { Do you have } \\
\text { mood swings? }\end{array}$ & Always-never & $5.5 \pm 2.7$ & $6.3 \pm 2.2$ & + & $5.4 \pm 2.5$ & $6.6 \pm 2.2$ & + & $5.4 \pm 2.7$ & $7.0 \pm 2.2$ & + \\
\hline Do you feel depressed? & Always-never & $6.1 \pm 2.5$ & $6.5 \pm 2.4$ & + & $5.7 \pm 2.2$ & $6.8 \pm 2.0$ & + & $5.6 \pm 2.8$ & $7.1 \pm 2.3$ & + \\
\hline $\begin{array}{c}\text { Do you have trouble } \\
\text { sleeping? }\end{array}$ & Very much-not at all & $6.7 \pm 2.8$ & $6.9 \pm 2.4$ & + & $6.4 \pm 2.4$ & $7.3 \pm 2.0$ & + & $6.6 \pm 2.7$ & $7.5 \pm 2.1$ & + \\
\hline $\begin{array}{l}\text { Lost of interest in } \\
\text { sexual activity }\end{array}$ & Always — not at all & $6.9 \pm 2.6$ & $7.8 \pm 2.1$ & + & $6.9 \pm 2.6$ & $7.8 \pm 2.1$ & + & $6.9 \pm 2.6$ & $7.8 \pm 2.1$ & + \\
\hline $\begin{array}{c}\text { Do you feel physically } \\
\text { attractive? }\end{array}$ & Not at all—always & $6.2 \pm 2.5$ & $7.2 \pm 2.2$ & + & $6.2 \pm 2.5$ & $7.2 \pm 2.2$ & + & $6.2 \pm 2.5$ & $7.2 \pm 2.2$ & + \\
\hline $\begin{array}{l}\text { Overall quality of life } \\
\text { during last month }\end{array}$ & Very poor-excellent & $6.0 \pm 2.3$ & $6.4 \pm 2.1$ & + & $5.6 \pm 2.0$ & $6.7 \pm 2.0$ & + & $5.7 \pm 2.7$ & $7.1 \pm 2.1$ & + \\
\hline
\end{tabular}

The higher the score on the VAS, the more positive the perception. VAS = Visual analog scale.

countries were statistically significant $(\mathrm{p}<0.0001)$ (Figure 3).

Body weight remained stable during the course of the study in Jordan and Lebanon (change over 6 cycles \pm 0.2 $\mathrm{kg}$ ) or even decreased in Syria (baseline: $66.3 \mathrm{~kg} \pm 11.3$ $\mathrm{kg}$; cycle 6: $65.7 \mathrm{~kg} \pm 11.1 \mathrm{~kg}$ ).

No pregnancies or deaths were reported.

\section{DISCUSSION}

We performed this multicenter, prospective, observational study to obtain information on bleeding pattern, clinical signs of water retention and patient satisfaction during day-to-day use. The observational approach of this study provides additional information to controlled prospective clinical trials, as in those studies the required degree of investigators' and volunteers' involvement might influence the selection of patients.

A total of 914 women were included from 3 countries in the Middle East as part of a sub-analysis that comprised 3,488 women in Europe, the Middle East and Canada [9]. The target parameters were bleeding pattern, clinical signs of water retention and patient satisfaction.

Our results of this sub-analysis confirm the trends seen in the overall evaluation reported in 2009 [9]: DRSP/EE drastically reduces intermenstrual bleeding, dysmenorrea (Figure 1), heavy bleedings (Figure 2) and signs of water retention like abdominal bloating and breast tenderness (Figure 3). In contrast, amenorrhea and incidence of swelling extremities remained relatively stable in Jor- dan which might be explainable be the high percentage of OC users at baseline (49.8\% in Jordan vs. $35.9 \%$ in Lebanon and $38.6 \%$ in Syria).

In our study the percentage of women with intermentstrual bleeding decreased from $37.4 \%, 48.7 \%$ and $32.2 \%$ at baseline to $9.7 \%, 6.1 \%$ and $10.9 \%$ at the end of cycle 6 in Jordan, Lebanon and Syria, respectively $(<0.0001)$. Our results are somewhat less pronounced compared to the findings of Parsey and Pong [2], who reported a decrease of intermenstrual bleeding from over $50 \%$ at baseline to less than 5\% after six cycles. Also, Huber et al. [1] found initial rates of intermenstrual bleeding over $60 \%$ dropping to $6.4 \%$ at cycle 6 and remaining at this level for up to 13 cycles. We assume that the lower baseline values might serve as an explanation.

Also, dysmenorrhea significantly decreased in all countries, most prominently in Lebanon, from $69.2 \%$ to $13.6 \%$. Foidart et al. [10] reported even lower incidence rates for dysmenorrhea of $4 \%$ over 26 cycles.

Amenorrhea decreased considerably in Lebanon and Syria but was relatively stable in Jordan. Again, our findings are less pronounced than those published by Parsey and Pong [2] who reported amenorrhea rates of $3.6 \%$ after 6 cycles with no further change up to the end of cycle 13 .

We saw a statistically significant decline in the percentage of women reporting abdominal bloating and/or breast tenderness from baseline to cycle $6(\mathrm{p}<0.0001)$. This decline of the two symptoms of water retention might be explained by the unique anti-mineralocorticoid 


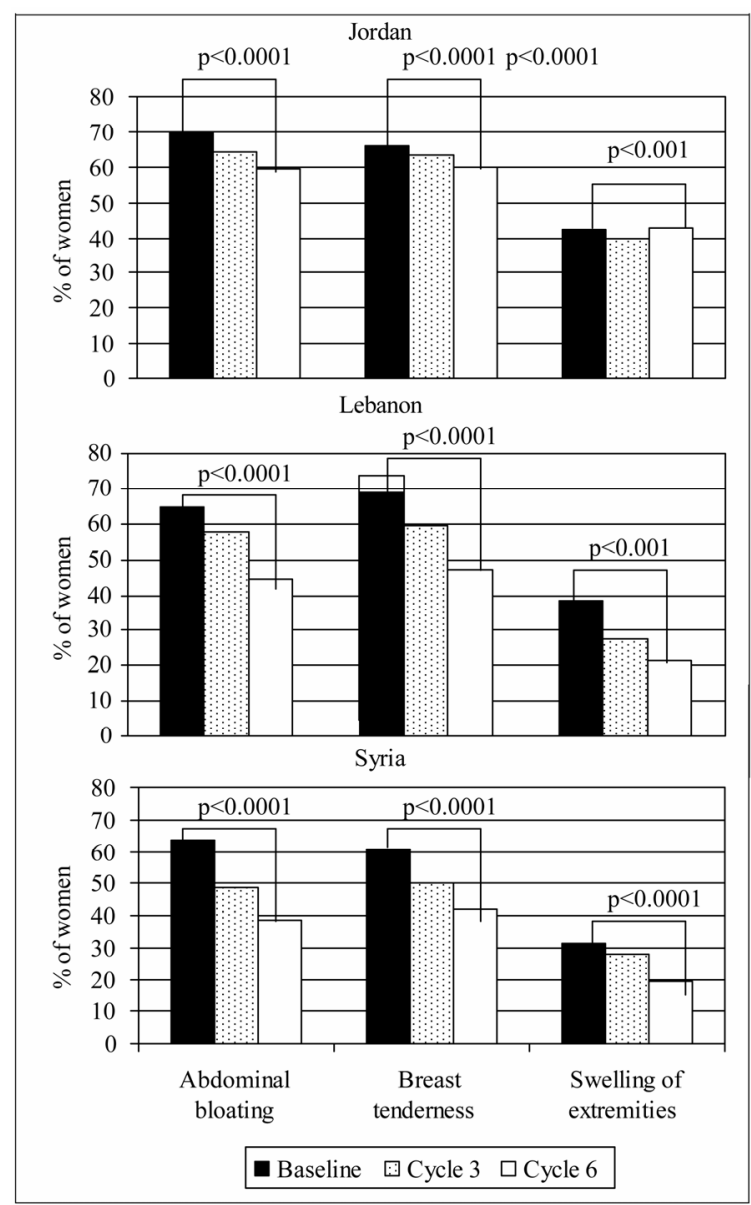

Figure 3. Pre-menstrual symptoms of water retention at baseline and after 3 and 6 cycles. The statistical tests were performed on the intensity of the symptoms (see statistical methods section). There was a significant alleviation of symptoms from severe and moderate towards mild although the number of women with symptoms depicted in the graphs for simplicity remained constant in some instances.

effect of the progestogen component, DRSP [4-7].

Bloating and breast tenderness are, amongst weight gain and skin blemishes, parameters of the Moos Menstrual Distress Questionnaire for symptoms of water retention [11,12] Endrikat et al. [13] showed that these symptoms decrease significantly in the premenstrual phase and to a lesser degree in the menstrual phase during treatment with DRSP/EE. Similar improvements were reported by other studies [14,15] Interestingly, Fruzzetti et al. [15] demonstrated that total body water and intracellular water were significantly lower after treatment with DRSP/EE in women affected by premenstrual syndrome. This effect was primarily associated with the luteal phase [16].

Patient satisfaction increased for all investigated items. Apter et al. [17] investigated the effects of DRSP/EE on general well-being and fluid-related symptoms using the
Psychological General Well-Being Index (PGWBI) and showed a significant improvement in the PGWBI total score and subscale scores (anxiety, depressed mood, positive well-being, self-control, general health and vitality) at cycles 3 and 6 . Similar improvements were found by Borges et al. [18] in 203 women taking DRSP/EE.

\section{CONCLUSION}

The oral contraceptive containing $3 \mathrm{mg}$ DRSP and 30 mcg EE has beneficial effects on bleeding patterns, signs of water retention and patient satisfaction.

\section{ACKNOWLEDGEMENTS}

This study was sponsored by Bayer Pharma A.G., Berlin, Germany. The authors would like to thank all participating women and investigators for their support of this research.

\section{REFERENCES}

[1] Huber, J., Foidart, J.M., Wuttke, W., et al. (2000) Efficacy and tolerability of a monophasic oral contraceptive containing ethinylestradiol and drospirenone. The European Journal of Contraception and Reproductive Health Care, 5, 25-34.

[2] Parsey, K.S. and Pong, A. (2000) An open-label, multi-centered study to evaluate Yasmin, a low-dose combination oral contraceptive containing drospirenone, a new progestogen. Contraception, 61, 105-111. doi:10.1016/S0010-7824(00)00083-4

[3] Dinger, J.C., Heinemann, L.A. and Kühl-Habich, D. (2007) The safety of a drospirenone-containing oral contraceptive: Final results from the European Active Surveillance Study on oral contraceptives based on 142,475 womenyears of observation. Contraception, 75, 344-354. doi:10.1016/j.contraception.2006.12.019

[4] Muhn, P., Krattenmacher, R., Beier, S., et al. (1995) Drospirenone: A novel progestogen with antimineralocorticoid and antiandrogenic activity. Pharmacological characterization in animal models. Contraception, 51, 99-110. doi:10.1016/0010-7824(94)00015-O

[5] Foidart, J.M., Oelkers, W. and Heithecker, R. (1995) Drospirenone: A novel progestogen with antimineralocorticoid and antiandrogenic activity: A major breakthrough in tomorrow's oral contraception. Gynecol Snapshot, 3, 1317.

[6] Fuhrmann, U., Krattenmacher, R., Slater, E.P. and Fritzemeier, K.-H. (1996) The novel progestin drospirenone and its natural counterpart progesterone: Biochemical profile and antiandrogenic potential. Contraception, 54, 243-251. doi:10.1016/S0010-7824(96)00195-3

[7] Oelkers, W., Foidart, J.-M., Dombrovicz, N., et al. (1995) Effects of a new oral contraceptive containing an antimineralocorticoid progestogen, drospirenone, on the reninaldosterone system, body weight, blood pressure, glucose tolerance and lipid metabolism. The Journal of Clinical Endocrinology \& Metabolism, 80, 1816-1821. 


$$
\text { doi:10.1210/jc.80.6.1816 }
$$

[8] Oelkers, W., Helmerhorst, F.M., Wuttke, W., et al. (2000) Effect of an oral contraceptive containing drospirenone on the renin-aldosterone system in healthy female volunteers. Gynecological Endocrinology, 14, 204-213. doi:10.3109/09513590009167683

[9] Endrikat, J., Milchev, N.P., Kapamadzija, A., Georgievska, J., Gerlinger, C., Schmidt, W. and Feroze, S. (2009) Bleeding pattern, tolerance and patient satisfaction with a drospirenone-containing oral contraceptive evaluated in 3488 women in Europe, the Middle East and Canada. Contraception, 79, 428-432. doi:10.1016/j.contraception.2008.12.007

[10] Foidart, J.M., Wuttke, W., Bouw, G.M., Gerlinger, C. and Heithecker, R. (2000) A comparative investigation of contraceptive reliability, cycle control and tolerance of two monophasic oral contraceptives containing either drospirenone or desogestrel. The European Journal of Contraception and Reproductive Health Care, 5, 124-134. doi:10.1080/13625180008500387

[11] Moos, R.H. (1968) The development of a menstrual distress questionnaire. Psychosomatic Medicine, 30, 843867.

[12] Moos, R.H. (1991) Menstrual distress questionnaire. Western Psychological Services. 12031 Wilshire Boulevard, Los Angeles.

[13] Endrikat, J., Sandri, M., Gerlinger, C., et al. (2007) A Canadian multicentre prospective study on the effects of an oral contraceptive containing $3 \mathrm{mg}$ drospirenone and 30 mcg ethinyl oestradiol on somatic and psychological symptoms related to water retention and on body weight. The European Journal of Contraception and Reproductive
Health Care, 12, 220-228. doi:10.1080/13625180701440818

[14] Brown, C., Ling, F. and Wan, J. (2002) A new monophasic oral contraceptive containing drospirenone. Effect on premenstrual symptoms. The Journal of Reproductive Medicine, 47, 14-22.

[15] Fruzzetti, F., Lazzarini, V., Ricci, C., et al. (2007) Effect of an oral contraceptive containing 30 microg ethinylestradiol plus $3 \mathrm{mg}$ drospirenone on body composition of young women affected by premenstrual syndrome with symptoms of water retention. Contraception, 76, 190194. doi:10.1016/j.contraception.2007.05.080

[16] Fruzzetti, F., Lello, S., Lazzarini, V., et al. (2007) The oral contraceptive containing 30 microg of ethinylestradiol plus $3 \mathrm{mg}$ of drospirenone is able to antagonize the increase of extracellular water occurring in healthy young women during the luteal phase of the menstrual cycle: An observational study. Contraception, 75, 199-203. doi:10.1016/j.contraception.2006.10.011

[17] Apter, D., Borsos, A., Baumgärtner, W., et al. (2003) Effect of an oral contraceptive containing drospirenone and ethinylestradiol on general well-being and fluid-related symptoms. The European Journal of Contraception and Reproductive Health Care, 8, 37-51.

[18] Borges, L.E., Andrade, R.P., Aldrighi, J.M., et al. (2006) Effect of a combination of ethinylestradiol 30 microg and drospirenone $3 \mathrm{mg}$ on tolerance, cycle control, general wellbeing and fluid-related symptoms in women with premenstrual disorders requesting contraception. Contraception, 74, 446-450.

doi:10.1016/j.contraception.2005.10.016 